\title{
Competências do professor no uso das TDIC e de ambientes virtuais
}

\author{
Rossana Mary Fujarra Beraldo \\ Universidade de Brasília - Brasília - DF - Brasil \\ Diva Albuquerque Maciel \\ Universidade de Brasília - Brasilia - DF-Brasil
}

\begin{abstract}
Resumo
As dinâmicas criadas em torno das tecnologias digitais e da Internet têm impulsionado mudanças na educação e resultado na necessidade de profissionalização de professores para o uso de ambientes virtuais, em uma nova cultura escolar. Com o objetivo de identificar competências pelo uso das TDIC em práticas de ensino, realizamos um estudo com quatro professores do ensino médio de uma escola pública no Distrito Federal, que utilizam a plataforma Moodle desde 2006. Com base na psicologia cultural, reunimos dados a partir de entrevistas gravadas em áudio, análise documental, consulta aos planos de aula e avaliação dos recursos tecnológicos. A análise construtivo-interpretativa dos dados focalizou cinco categorias: Sou autodidata, Sou motivado, Faço a diferença, Construo o novo e Co-construo com o grupo. Os resultados indicaram que a aprendizagem coletiva, o estabelecimento de recursos simbólicos e os aspectos emocionais entre esses professores incidiram positivamente no desenvolvimento de novas competências para lidar com ambiente virtuais.
\end{abstract}

Palavras-chave: Psicologia cultural; redes sociais; competência.

\section{Teacher skills in the use of TDIC and virtual environments}

\begin{abstract}
The dynamic created around the digital and Internet technologies have driven change in education and results in the need for teacher improving professional search for the use of virtual environments in a new school culture. In order to identify skills for the use of TDIC in teaching practices, we conducted a study with four high school teachers of a public school in the Federal District, using the Moodle platform since 2006. Based on the cultural psychology, gather data from audio recorded interviews, document analysis, consultation with lesson plans and assessment of technological resources. The constructive-interpretative data analysis focused on five categories: I am self-taught, I am motivated, I make a difference, we build the new Co-build with the group. The results indicated that the collective learning, the establishment of symbolic resources and the emotional aspects of these teachers, contributed positively in the development of new skills to handle virtual environment.
\end{abstract}

Keywords: Cultural psychology; social networks; competence.

\section{Competencias del profesor en el uso de las TDIC y de ambientes virtuales}

\section{Resumen}

Las dinámicas creadas en torno de las tecnologías digitales y de la Internet ha impulsado cambios en la educación y resultado en la necesidad de profesionalización de profesores para el uso de ambientes virtuales, en una nueva cultura escolar. Con el objetivo de identificar competencias por el uso de las TDIC en prácticas de enseñanza, realizamos un estudio con cuatro profesores de la enseñanza intermediaria de una escuela pública en el Distrito Federal, que utilizan la plataforma Moodle desde 2006. Con base en la psicología cultural, reunimos datos a partir de entrevistas grabadas en audio, análisis documental, consulta a los planes de clase y evaluación de los recursos tecnológicos. El análisis constructivointerpretativo de los datos focalizó cinco categorías: Soy autodidacta, Estoy motivado, Hago la diferencia, Construyo el nuevo y Co-construyo con el grupo. Los resultados indicaron que el aprendizaje colectivo, el establecimiento de recursos simbólicos y los aspectos emocionales entre esos profesores incidieron positivamente en el desarrollo de nuevas competencias para lidiar con ambiente virtuales.

Palabras clave: Psicología cultural; redes sociales; competencia. 


\section{Introdução}

As Tecnologias Digitais de Informação e Comunicação (TDIC) (Joly, Silva, \& Almeida, 2012; Scorsolini-Comin, 2014), como ferramentas mediadoras em atividades sociais permitem aos indivíduos participarem de múltiplos contextos de desenvolvimento social e cognitivo, sejam eles de aprendizagens formais ou informais.

Expor e discutir as mudanças advindas da virtualização do corpo, dos objetos e dos espaços de interação (Lévy, 1996) exige negociações de significados que são construídos em um novo fazer coletivo e requer novas formas de pensar a educação. A profissionalização de professores para o uso de ambientes virtuais e contextos mediados por TDIC é destacada neste trabalho, tendo como base os resultados de estudo realizado com quatro professores do ensino médio da rede pública que buscaram inovar suas aulas utilizando uma plataforma de aprendizagem.

Retomando alguns projetos promovidos pelo Ministério da Educação (MEC) para a inserção das TDIC, podemos mencionar o Mídias na Educação iniciado em 2001, que visou incorporar os programas da Secretaria de Educação à Distância do Ministério da Educação (Seed/MEC) como o TV Escola, Proinfo, Rádio Escola e Rived (Ministério da Educação, 2015). Já as políticas públicas de conectividade, o projeto Banda Larga nas Escolas (Tancredi, 2008), que embora tenha permitido aos professores o acesso à conexão em alta velocidade, deixou faltar uma política clara sobre segurança do uso da rede, resultando na utilização de ferramentas de rede sociais como Blogger, Orkut, Picasa, Facebook, Twitter, Skype, WhatsApp, Facetime, Instagram ou e-mail pessoal. Esses recursos foram empregados por professores, contudo, sem que houvesse um respaldo institucional que garantisse o direito de uso de imagem, som, conteúdo e autoria (Beraldo, 2013).

O projeto Um computador por aluno (UCA), iniciado em 2010, também administrado pelo MEC, apontou baixos índices de aproveitamento (Lavinas \& Veiga, 2013), sendo o foco direcionado, sobretudo, para o manejo tecnológico. Sobre isso, ressaltamos que interagir com as tecnologias e interagir com os outros em contextos mediados por tecnologias gera processos de aprendizagem diferentes. Em outras palavras, os softwares e jogos educacionais, por exemplo, são configurados a partir de códigos, onde estão inscritas as regras, probabilidades e recompensas para conquistar o objetivo. Interagir com os outros por meio de tecnologias abre uma gama de possibilidades, visto que as regras dadas a priori são negociadas e transformadas no decorrer da atividade (Leontiev, 1992; Engeström, 2007). Não há limites para a mente humana; em conversações, vamos de um conhecimento a outro por meio de negociações, argumentações, tensões, acordos e desacordos (Bakthin, 1993, 1994; Wertsch, 1988; Matusov, 1996; Brown \& Reshaw, 2006). O princípio dialógico baseia-se nesta diferença, ou seja, as pessoas dialogam sobre o mesmo objeto sob vários pontos de vista.
Projetos similares de formação de professores como - Programa Nacional de Tecnologia Educacional (Proinfo Integrado), têm por objetivo a formação de professores do ensino médio para atuarem no projeto Um Tablet por Aluno (UTA) - resultado da parceria entre o Fundo Nacional de Desenvolvimento da Educação (FNDE) e o Ministério da Educação (Lorenzoni, 2012). Sobre isso, observamos a necessidade de profissionalização do professor para o uso de ambientes virtuais, recursos abertos e elaboração de planos de aulas mais conexos com as potencialidades das TDIC.

Dentro dessa temática e considerando projetos experimentais que apresentaram bons resultados, podemos destacar o Educomunicação pelas Ondas do Rádio criado pelo Núcleo de Comunicação e Educação da Universidade de São Paulo (NCEUSP) (http://www.usp.br/nce/aeducomunicacao/), em que professores e alunos utilizam o rádio e computadores para projetos integrados às práticas curriculares. Já no projeto Mídias e Tecnologias Educacionais Livres, que é coordenado pela Secretaria de Educação da Bahia, os professores e alunos compartilham objetos por simulação, jogos, vídeos, áudio e conteúdo. A partir dessa iniciativa, foi criado o projeto audiovisual Programa Intervalo, que vai ao ar pela TV Educativa da Bahia (TVE/Canal 2) em que os estudantes são os próprios protagonistas de várias temáticas contemporâneas (www.educacao.ba.gov.br/intervalo). Esses projetos são iniciativas locais e com gestão compartilhada - entre coordenadores, professores e alunos -, a partir de uma demanda que surge de circunstâncias geradas na comunidade escolar, pois o que fazem juntos tem sentido e a 'melhor' tecnologia tem um aspecto relacional com as vivências do cotidiano.

Celulares, notebooks, softwares de edição de imagem e som, câmeras de vídeo, GPS, iPads conectados à rede, por exemplo, são recursos potenciais que podem ser integrados em atividades de iniciação científica a partir de dados da Internet, mecanismos de busca, ferramentas de visualização ou plataformas de aprendizagem na produção coletiva (Beraldo \& Barbato, 2013; Versuti, Beraldo, \& Gosciola, 2014). As escolas estão repletas das TDCl introduzidas formalmente através de projetos do governo ou secretarias de educação e, informalmente, pelos estudantes e professores quando usam seus dispositivos digitais. Desse modo, que sentido tem manter os estudantes enfileirados com notebooks ou tablets de última geração sem aproveitar pedagogicamente o potencial das redes? O que falta para incluir as TDIC na sala de aula?

Considerando esses questionamentos, buscamos apresentar neste artigo os resultados de um estudo realizado com quatro professores do ensino médiode uma escola pública em Brasília, onde se utiliza a plataforma Moodle (Modular Object Oriented Distance Learning), desde 2006. Buscamos compreender como estes professores vêm enfrentando a necessidade de mudança do fazer em sala de aula, o que aprenderam na prática e que competências desenvolveram a partir do emprego das TDIC no fazer diário (Beraldo, 2013). 


\section{Práticas escolares em contextos mediados pelas TDIC}

Contextos mediados pelas TDIC demandam ambientes de trabalho com distribuição das tarefas, gestão da informação e responsabilidade entre professor e estudantes. A iniciação científica - projetos, seminários, portfólios, estudo de campo - pode ser considerada no planejamento pedagógico, a partir do interesse e do conhecimento prévio dos estudantes. A cultura comporta os recursos simbólicos, os quais são manipulados e (re)combinados pelos sujeitos. Diante do volume de dados e informações na Web, é essencial transitar por espaços que estão além dos muros da escola. É necessário 'ensinar a pensar' e isto requer a capacidade de abstrair conceitos, selecionar (minerar) e manipular dados e informações. A Web é um organismo vivo, alimentado em tempo real pela colaboração de seus usuários e a escola já está interconectada neste universo móvel e ubíquo. Isso não quer dizer que professores deixarão de utilizar as tecnologias existentes, ao contrário, trata-se da transição da escola para modelos híbridos, com o emprego de dispositivos analógicos e digitais.

O que temos observado é que quando as TDIC são introduzidas na disciplina, o papel do professor é destacado, seja para manter um bom nível de compreensão do tema e das proposições ou para tornar o contexto de aprendizagem potencial - quando coloca novos questionamentos e inter-relaciona o conteúdo com outras áreas do saber. Por exemplo, em atividades colaborativas em que professores e estudantes podem fazer visitas virtuais intercaladas por pesquisa de campo a oceanários, museus, casas de cultura, planetários ou projetos de preservação (Beraldo \& Barbato, 2013). Usar as TDCl para uma videoconferência, a sala de aula pode estar conectada em qualquer ponto do planeta, onde um pesquisador, autor de livro, especialista em determinada área ou até estudantes de outras escolas, podem discutir temas relativos ao conteúdo da disciplina. São ideias que não requerem alto investimento e sim novos métodos para usar as TDIC e a rede de uma forma produtiva e contextualizada.

As TDIC e o acesso à Internet são apenas 'recursos' ou 'meios' que vão auxiliar o professor na mediação de um tema. Em primeiro plano, estão as 'relações humanas' e isso requer uma aproximação com o cotidiano dos estudantes para fazer emergir processos de identificação, identidade (Ligorio, 2010), posicionamentos discursivos (Brown \& Renshaw, 2006), espaços de conversação (Mercer, 2000; Pontecorvo, Ajello, \& Zucchermaglio, 2005). Se considerarmos o conceito de zona de desenvolvimento proximal (ZDP) proposto por Vigotski (2009),em que o sujeito necessita de um par mais competente para realizar uma atividade vamos perceber que as novas gerações são, em sua maioria, mais competentes no uso tecnológico e na navegação pelo ciberespaço do que seus próprios professores (Palfrey \& Gasser, 2011; Serres, 2013). Contudo, dados e informações disponíveis na Web devem ser filtrados (minerados) e discutidos na escola. Se os professores se permitirem compartilhar com os estudantes essa responsabilidade, poderão dedicar mais tempo para elaborar planos de aula mais contextualizados às vivências diárias dos alunos.

Quando se trata de profissionalização de professores para ambientes virtuais e uso das TDIC, a criatividade e a inovação são capacidades importantes. Oliveira (2010), por exemplo, ressaltou em seu estudo algumas características potenciais do professor criativo. Segundo a autora, o profissional deve estar aberto às novas experiências e mudanças, ter ousadia e ser curioso, deve ter confiança em si próprio, buscar desenvolver ideias inovadoras e ampliar seus pontos de vista para fazer escolhas. A esse respeito, Maciel e Raposo (2010) reiteram que além de o educador estar aberto à experimentação deve empregar suas experiências prévias para explicitar suas crenças e valores no processo de construção do seu saber pedagógico. Observa-se, então, que estamos propondo uma outra lógica de pensar o plano de aula, o que requer uma pedagogia mais alinhada às funcionalidades dos dispositivos digitais ou tecnologias híbridas oferecem, além dos recursos humanos e materiais no contexto escolar (Beraldo, 2013).

\section{Metodologia}

O método geral, sob a perspectiva da psicologia cultural, teve por base a análise construtivo-interpretativa objetivando a compreensão da posição pessoal de cada um dos professores entrevistados e em relação à comunicação que foi construída com a pesquisadora. Os procedimentos de construção de dados constaram de entrevistas gravadas em áudio, com base em roteiro semiestruturado e, construído a partir de informações disponibilizadas pela escola, como: o Projeto Político Pedagógico (PPP), consultas aos planos de aula e verificação das salas de aula na plataforma (ferramentas e recursos). Em um primeiro contato com a escola, convidamos os professores que empregam a plataforma e/ou outros dispositivos digitais nas disciplinas. Seis professores colocaram-se à disposição e, após conversas, nos horários convenientes a eles. Convidamos quatro professores, considerando que eles a utilizam com frequência e foram capacitados no Moodle pela Universidade de Brasília, em parcerias ocorridas em 2006 e 2008. A seguir, detalhamos o estudo com a finalidade de dar mais clareza ao nosso argumento.

\section{A Escola pesquisada}

A pesquisa foi realizada em uma escola da rede pública de ensino médio, situada em uma das principais cidades do Distrito Federal. Atende a formação básica do $1^{\circ}, 2^{\circ}$ e $3^{\circ}$ ano do ensino médio, nos períodos matutino, vespertino e Educação de Jovens e Adultos (EJA), no período noturno, totalizando aproximadamente 3.000 estudantes e 185 professores (do quadro e temporários). Nesta escola, os professores permanecem na sala de aula e os alunos mudam de sala, sendo que há dois intervalos de 15 minutos. 
As salas estão equipadas com televisores LCD, aparelho de vídeo, datashow e quadro negro; entretanto, os professores não têm acesso à Internet nas salas de aula. Estão disponíveis no Laboratório de Informática 32 computadores (em bom estado, mas não suficientes em relação ao número de alunos) e conexão banda larga. Equipamentos e móveis estão dispostos no mesmo layout da sala de aula e o professor tem um quadro negro à disposição, além das lousas digitais (Projetores Proinfo, porém, não integrados). O Moodle foi implantado nesta escola pelos próprios professores e, quando a pesquisa foi realizada, havia 48 salas online ativas. $O$ servidor onde está instalada a plataforma não é exclusivo (compartilhado) e tem baixa capacidade de armazenamento, visto que é um projeto mantido com recursos da própria escola, eles utilizam também o programa Linux, recomendado pelo MEC.

\section{Participantes}

Participaram desta investigação quatro (4) professores do quadro efetivo da escola. Os professores Luís e Ana realizaram o curso de capacitação no Moodle, em 2006 e 2008, a professora Bia em 2008 e a professora Julia em 2006 (nomes fictícios). Seus respectivos perfis profissionais são apresentados na Tabela 1.

\section{Procedimentos de análise}

Em um primeiro nível de análise das transcrições das entrevistas, realizamos várias leituras dos dados com a finalidade de observar similaridades ou recorrências. Os recortes selecionados foram primeiro observados individualmente (por professor) e, depois, cotejados entre si, buscando-se identificar elementos que nos orientassem na construção de categorias de análise. A partir dessa primeira apreciação e da reunião das demais informações, construímos cinco categorias que foram úteis na análise construtivo-interpretativa: (01) Sou autodidata, (02) Sou motivado, (03) Faço a diferença, (04) Construo o novo e (05) Co-construo com o grupo. Nesse sentido, foram valorizados os argumentos que reforçavam a tomada de decisão coletiva, a reflexão de si e do outro, a emoção na narrativa de eventos pessoais e os sentidos construídos a partir da experiência coletiva.

\section{Resultados}

As cinco categorias de análise apresentadas possibilitaram a delimitação de algumas características relevantes na identificação de processos ontogenéticos, observando-se que os recortes das falas nas entrevistas estavam carregados de significação social e subjetiva. Compreender como tal realidade foi culturalmente organizada - em sua dimensão simbólica (recursos semióticos) e interacional (das práticas sociais) - a partir das narrativas desses professores, foi também preocupação da nossa análise. Ficou destacado por esses educadores que o uso da plataforma ocorreu de modo gradativo; tiveram que tomar várias decisões para superar os desafios e limitações próprias da época, como: internet discada, servidor com baixa capacidade, problemas de segurança de rede, poucos computadores e literatura, praticamente, inexistente na área (em língua portuguesa).

Verificamos que os professores entrevistados têm características pessoais similares que ficaram evidenciadas em diversos trechos de suas falas, destacadas e analisadas a seguir. Observamos que participar de cursos ou pesquisar por si era algo prazeroso, uma atitude autoconsciente com vistas à solução dos problemas que iam surgindo, foram

Tabela 1. Perfil profissional dos entrevistados.

\begin{tabular}{|c|c|}
\hline Participante & Dados sobre o perfil \\
\hline Prof. Luis & $\begin{array}{l}\text { Graduado em Matemática, especialista em Docência para a Educação Formal, fez curso de } \\
\text { configurações de rede, microinformática, foi professor-tutor na Universidade Aberta do Brasil, atua } \\
\text { no quadro da secretaria há } 19 \text { anos, sendo responsável pelo Laboratório de Informática da escola. }\end{array}$ \\
\hline Profa. Ana & $\begin{array}{l}\text { Fez curso Normal e graduou-se em Letras, especialista em Economia, participou da implantação } \\
\text { do Programa de Avaliação Seriada (PAS), cursou o Programa TV Escola Desafios de Hoje, fez } \\
\text { curso de configuração em redes e microinformática e diversos cursos de curta duração à distância. } \\
\text { Atua como professora há quase } 30 \text { anos. }\end{array}$ \\
\hline Profa. Bia & $\begin{array}{l}\text { Graduada e especialista em Matemática. Foi tutora de cursos à distância e usou plataforma } \\
\text { educacional em instituição particular. Atua nesta escola há } 19 \text { anos. }\end{array}$ \\
\hline Profa. Julia & $\begin{array}{l}\text { Graduada e especialista em Química. Fez diversos cursos de atualização, trabalhou no Centro de } \\
\text { Processamentos de Dados do Ministério da Justiça como técnica em informática e está no quadro } \\
\text { de professores da Secretaria de Estado de Educação do Distrito Federal há mais de } 22 \text { anos. Foi } \\
\text { diretora da escola pesquisada e atualmente coordena uma Regional de Ensino em Brasília. }\end{array}$ \\
\hline
\end{tabular}


aplicando a teoria à prática. À época, plataformas de aprendizagem estavam sendo testadas pelas universidades, um projeto em escola pública era um grande desafio. A insistência em manter essa plataforma na escola exigiu que se tornassem autodidatas para o aprendizado e persistentes na descoberta de soluções. A seguir, comentamos cada categoria a partir de extratos que consideramos representativos para a discussão.

Categoria 01 - Sou autodidata - Para análise desta categoria utilizamos eixos norteadores na interpretação, como: (a) tomada de consciência pela pessoa sobre si mesma e sobre seu papel em meio aos outros sociais, (b) suas decisões baseadas em experiências prévias que são orientadas para ações futuras e (c) interação com o grupo para resolução dos desafios que surgem.

Com a entrada do Programa Banda Larga nas Escolas (PBLE) -criado pelo Ministério da Educação em 2008, a escola passou a usar conexão via wireless e a partir dessa iniciativa, alguns professores começaram a usar ferramentas de redes sociais, sem conhecer bem seu alcance. Em consequência, sobreveio a falta de segurança pela exposição na rede. O professor Luis, que era o coordenador do laboratório de informática, disse que fez diversas pesquisas na Internet, mas que a ideia de usar a plataforma de aprendizagem surgiu de conversa com uma tutora da Universidade Aberta do Brasil (UAB). Observa-se no extrato a seguir que o diálogo interno vai orientando-o para a busca de uma solução, o que amplia o seu campo de visão para o alcance de metas em um processo bidirecional em relação ao grupo (Maciel, Branco, \& Valsiner, 2004). Mediante diversas possibilidades, o sujeito percebe o seu ambiente simbólico e ativa conhecimentos de suas experiências prévias, de modo que é definido um campo de ação. A tomada de decisão não acontece num vácuo, está vinculada à ação coletiva em meio aos artefatos-mediadores e objetos-orientadores em dada cultura (Engeström, 2007). O sujeito se reporta ao vínculo que tem no coletivo, como se observa na fala do professor Luis:

... eu pensei...- eu preciso de alguma coisa que eu possa centralizar, mas centralizar de uma forma positiva, as ações da escola e que possa oferecer esses serviços aos professores, que se consiga ter um treinamento adequado, que a gente consiga ter uma resposta pedagógica melhor.

A fim de solucionar o problema aqui configurado como falta de segurança no uso de ferramentas de redes sociais por professores e alunos, sobreveio a ideia de saber mais sobre o software Moodle. Assim, pesquisou sobre o assunto e verificou que a ferramenta era adequada aos propósitos dos professores e da escola, como mostrado no recorte a seguir.

Eu pensei: "olha isso aí é muito bom, isso aí nos serve" e, então, eu comecei a ir atrás, a pesquisar e ir atrás de quem pudesse nos ajudar. Assim, eu comecei e fiz uma espécie de pequeno projeto e comecei a startar.
Nesses trechos, observamos que a narrativa do professor Luis caminha da superação da fase inicial de busca para uma intencionalidade mais concreta no sentido do alcance de novas metas, sendo seu objetivo reorganizado para uma nova forma de ação dirigida para o futuro, em que os vínculos externos autorregulam sua ação (Leontiev, 1992). A elaboração lógico-conceitual na resolução de problemas, observada aqui, conduz à manipulação de conceitos abstratos e pensamento prospectivo, na qual o indivíduo pode intuir, imaginar, criar, generalizar, (re)combinar vínculos de situações vivenciadas, não só do problema na situação, como também dos que poderão decorrer de uma ou outra escolha. Sobre isso, Wegerif (2005) destaca que a criatividade está relacionada à avaliação, questionamentos e trechos de diálogos que vão sendo configurados em um campo de significação e que transitam quando um passa a palavra ao outro, como uma orientação intersubjetiva.

A professora Ana, que também participou do projeto com o Moodle desde o início, contou-nos que quando surgiram novas tecnologias como o DVD e o computador, decidiu fazer uma série de cursos de capacitação em rede. Para ela, ser autodidata é essencial, como destacou:

Gosto do que faço e não abro mão de inovar, de acompanhar os avanços tecnológicos como ferramenta para a melhoria da qualidade do ensino. Importa-me, como professora, criar e recriar novos modos de ensinar e aprender, não gosto da mesmice. Penso que cada ser é um ser diferente, com sua própria identidade. Cabe a mim, portanto, enquanto mediadora da aprendizagem, promover atividades favoráveis ao desenvolvimento dos alunos, para que eles tenham sua própria autonomia e organização.

Por sua vez, a professora.Bia afirmou, em vários trechos, que é autodidata e que aprendeu a navegar sozinha:

“... o que a gente aprende de tecnologia é você fuçando, meu marido brinca comigo porque eu já detonei uns três computadores, eu começo a fuçar a fuçar depois...puff". Falou também: "Ah já tem pelo menos uns cinco anos, tem cinco anos que eu tenho procurado tirar a matemática do quadro e do gi".

Nessa fala, a professora explicita que optar por uma ou outra tecnologia passa por tentativas e pela apropriação de técnicas que vão sendo internalizadas, como destacado nos estudos de Vigotski (2009) sobre as mudanças na lógica interna do fazer quando da entrada de novas ferramentas no meio social e, consequentemente, modificações na comunicação, linguagem e distribuição dos papéis entre as pessoas em um grupo de trabalho.

Categoria 02 - Sou motivado - Muitos dos aspectos relacionados à motivação têm pontos em comum como o interesse, persistência, determinação, aspiração e realização pessoal. A motivação pode estar relacionada aos laços afetivos, às formas de filiação, a uma responsabilidade tomada perante um grupo ou pelo fato de o sujeito se sentir ame- 
açado em uma relação hierarquizada. A motivação ocorre ainda quando do retorno de uma recompensa, por pressão ou quando a pessoa se sente motivada em uma atividade pelo simples prazer em realizá-la (Rueda \& Moll, 1994), principalment, no que se refere à satisfação pessoal e aos sentimentos de competência, cujo estímulo é orientado para que o indivíduo persista para alcançar seu objetivo, seja por meio da motivação extrínseca ou intrínseca. De acordo com Deci (1992) e Maciel (2008), as necessidades psicológicas mais frequentes relacionadas com a motivação intrínseca são a competência e a autodeterminação (ou autonomia), embora a necessidade de relacionamento afetivo e motivacional com os pares seja também um fator preponderante. A motivação está vinculada à emoção, mobiliza o sujeito para o desenvolvimento de outras fases da atividade, de modo qu, os registros emocionais que se integram em diferentes momentos no interior de uma atividade "são extremamente variáveis, o que rompe com a visão estática e homogênea de motivação" (Rey, 2003, p. 246).

Intimamente relacionado à motivação, o interesse é entendido como um sentimento de autodeterminação em que se observam aspectos importantes como necessidades psicológicas intrínsecas entre o interesse pessoal e o interesse situacional em que a pessoa tem maior engajamento com uma causa, manutenção de forte vínculo emocional/valorativo, sentimentos de competência em relação aos pares e consigo mesma, de forma que dedica mais atenção e um desejo permanente de interagir com pessoas relacionadas à área de seu interesse. Em nosso estudo, observou-se que esses professores estavam motivados e/ou interessados em usar a plataforma, mesmo com os obstáculos à época. $\mathrm{O}$ professor Luis fez o seguinte relato:

... então a ideia era fazer uma turma piloto, essa era a ideia do projeto, mas quando os professores fizeram [a capacitação em Moodle], eles ficaram empolgados, então, eles queriam usar imediatamente. la entrar primeiramente duas turmas, mas todos os professores que fizeram o curso, falaram: "não, a gente fez o curso e a plataforma taí e, os alunos tão matriculados, vamos startar este negócio e colocar para funcionar". E praticamente, naquela época, todos os professores começaram a utilizar.

Desse trecho podemos inferir que a apropriação das TDIC não ocorre de maneira uniforme; há erros, acertos, descobertas e convencionalização de recursos simbólicos e, assim, é criada a prática cultural. Sobre essa questão, a professor. Bia relata que o uso da plataforma Moodle possibilitou tempo mais estendido para que os estudantes resolvessem cálculos matemáticos em casa e, quando estavam em sala de aula, podiam explicar como resolveram o problema, onde pesquisaram e aplicaram o que aprenderam. Ela relata:

... coloquei um comentário e pedi para eles simplesmente discutirem entre si. Dei um mês na plataforma. Eles simplesmente começaram a pesquisar, pesquisar, pesquisar, quando eu entrei em sala de aula o que eu não tinha imaginado eles fizeram. Eu pensei em fazer o conceito e aí o aluno chegava e falava assim: "ah, não professora eu já vi isso na internet, lá na plataforma PA, progressão aritmética é isso, isso e isso", "ah, (continuou o aluno) mas eu também vi a geométrica". Quando eu percebi, eles já tinham aprendido tudo sobre progressão aritmética e geométrica.

Neste recorte, observa-se que a professora divide a responsabilidade da aprendizagem com seus alunos, a considera o papel ativo dos estudantes e isso instaura campos afetivos mais permeáveis à participação (Maciel, Branco, \& Valsiner, 2004).

Categoria 03 - Faço a diferença - A cultura tem grande importância para o desenvolvimento da pessoa e as práticas culturais são essenciais para a constituição do indivíduo. Os papéis atribuídos ou assumidos dentro de uma prática social envolvem relações cognitivas complexas para seu funcionamento, conceituada como 'inter-pensar' (interthinking) (Littleton \& Mercer, 2013) em que os sujeitos discutem e chegam a um acordo consensual para enfrentar as restrições (constraints) e possibilidades (affordances) do contexto (Bereiter, 1997). Por meio de um 'juízo' perceptivo, o grupo intui quem está mais apto para assumir ou realizar algum tipo de tarefa. Desse modo, o conceito -Faço a diferença- busca evidenciar como as dinâmicas de intersubjetividade (Beraldo, no prelo) são estabelecidas no coletivo em contextos mediados por ferramentas culturais. Fazer a diferença em um grupo envolve afetividade e emoção porque é "uma condição da atividade humana dentro do domínio da cultura" (Rey, 2003, p. 242). O professor Luis destacou que sempre é requisitado na construção das disciplinas na plataforma:

O professor pergunta: "dá pra fazer? Como é que funciona?". Eu falo: "funciona, funciona muito bem! Parabéns, vamos em frente!" Ou às vezes eu falo:"olha, essa atividade ficaria mais bem formatada de outra forma, entendeu? Às vezes trazer a turma até aqui não seria producente." Então a gente vai negociando com total liberdade e quando tem problemas técnicos que a plataforma possa de alguma forma gerar, os professores têm total confiança, eu resolvo aqui ...

Mediante diversas possibilidades, a experiência de agir de determinada forma e, por repetidas vezes, criar uma prática cultural, que é transformada em recursos simbólicos, mais ou menos estáveis, pode indicar maior afinidade de ideias entre o grupo. Já para professora Ana, fazer a diferença entre os colegas de trabalho é partilhar conhecimentos, ter experiências, saber ouvir e confiar no outro. Ela relata:

... a Educação, ela foi feita pra abrir, se você fechar você perde de aprender também, tem que trocar com o outro, às vezes se você começa a me ensinar e eu coloco minhas ideias nela e quando eu coloco minhas ideias eu posso florescer, eu posso melhorar. Educação não pode ser assim, educação tem que ser assim [...]. Se você sabe que ela é assim, a tendência é crescer mais galhos, se coloca uma 
plantinha no vaso com a raiz presa ela não cresce, ela fica ali por isso que vira essas plantinhas (Pesquisadora: bonsai)). É! Bonsai é que bota num vasinho tão pequeno que ela vai ficando e se a gente abre para o sol ela cria ramos e pode dar muitos frutos e coisas melhores.

Categoria 04 - Construo o novo- Construir o novo requer a internalização e externalização da cultura coletiva e pessoal em reconstruções no plano intrapsicológico pela troca de materiais semióticos e perceptivos com o ambiente (Valsiner, 2012). O processo de internalização é sempre construtivo porque transforma o material externo em uma forma interna diversa, mesmo do caso de uma 'tradução' ou 'aquisição', sendo o princípio geral da construção mantido pelas variantes e (inter)níveis de significação. A externalização refere-se ao processo inverso, sendo que os materiais-culturais intrapsicológicos carregam em si uma nova reconfiguração em que estão reunidas partes da cultura pessoal (autoria) e partes da cultura coletiva. Em consequência, o conceito Construo o novo caracteriza-se pela autoria, pela recriação dos materiais simbólicos abertos, inconclusos e dinâmicos que permeiam a realidade social em uma construção inédita, mas que contém em si traços de sua própria origem. Com essas considerações, apresentamos a narrativa da professora Julia sobre um projeto transdisciplinar ocorrido em 2010.

... no ano de 2010, nós fizemos uma leitura de livro usando o Moodle. Então, era a leitura do livro 'A ciência através dos tempos'. Os alunos tinham que postar os resumos, tinham os fóruns para debater cada capítulo. Semanalmente era um capítulo lido, em seguida, os alunos postavam o resuminho individual e participavam do fórum e, no final, tinham que fazer um vídeo. Dividimos em duas etapas as leituras, no primeiro semestre fizeram um vídeo e depois outro vídeo e eles tinham que entregar em DVD. A gente tinha uma escala de mostra destes vídeos, três turmas assistiam aos três vídeos e assim por diante, é um trabalho e tanto, né? É trabalhoso e eles fazem, tivemos vídeos excelentes, muitos bons e nós ficávamos além do nosso horário assistindo aos vídeos.

Este pode ser um exemplo inovador de transição da escola para modelos híbridos de ensino, mesclando recursos analógicos e digitais.

Categoria 05 - Co-construo com o grupo- Para a psicologia do desenvolvimento o sujeito tem papel ativo, intencional e constitutivo na cultura. Assim, o conceito Co-construo com o grupo pressupõe ajuda mútua, engajamento crítico e consideração pelos colegas no alcance de metas. Sobre esse tema a professora Bia conta-nos que busca desenvolver mecanismos que facilitem o trabalho de todos; um exemplo é o uso do diário eletrônico de classe: "Eu sento com eles e converso e a gente troca ideias, às vezes eles chegam e falam: olha, eu queria fazer isso, o que você acha?". Retomando um extrato citado anteriormente, o professor Luis relata: "Dá pra fazer? Como é que funciona?
Eu falo - funciona, funciona muito bem. Parabéns, vamos em frente!"

Co-construir permite o abandono de suposições e crenças entre o grupo, permitindo assim a diversidade e o desenvolvimento de novas ideias e métodos. Muitas práticas são extintas por não considerarem a diversidade de aptidões entre os participantes, outras são fortalecidas porque mudam juntamente com a inclusão de diferenciações colocadas por outros indivíduos. Nesse sentido, pensar com o outro pode ser um caminho para a transição de tempos mais velozes e outros espaços de aprendizagem que a escola deverá ocupar.

\section{Considerações Finais}

Observar como esses professores organizam as práticas escolares, em contextos mediados por TDIC indicaram que a escola tem um papel efetivo como instrumento desencadeador de desenvolvimento e conhecimento humano. As novas formas de ensino e aprendizagem exigem posturas mais abertas, dialógicas e emancipatórias. É indispensável descentralizar os saberes diante de uma escola 'sem paredes'. Não se trata de informatizar ainda mais o ambiente escolar, mas discutir como processos de virtualização transformam a prática pedagógica e as dinâmicas em sala de aula. Em termos teóricos, buscamos colaborar para a profissionalização de professores para o uso das virtualidades da rede e apropriação das tecnologias digitais (ou híbridos, analógicos e digitais), o que requer novos estudos nessa temática. Nesse sentido, aprender e ensinar utilizando o aparato tecnológico requer a reflexão dos professores para assumirem um novo papel no processo de ensino aprendizagem, o que envolve uma mudança pessoal e cultural.

As TDIC são ferramentas com grande potencia ; contudo, dar a elas maior status, aumentará ainda mais o distanciamento dos estudantes, considerando que estamos na terceira geração de nativos digitais. Por mais sofisticada que seja a tecnologia nada substitui a presença do professor, porque a aprendizagem vai além dos conteúdos da disciplina. Estudantes vão à escola para se socializar, para viver a cultura, aprender uns com os outros, expressar emoções, criar vínculos e relações afetivas para se desenvolver.

\section{Referências}

Bakhtin, M. M. (1993). Estética da criação verbal. São Paulo: Martins Fontes.

Bakhtin, M. M. (1994). Speech genres and other late essays. Austin, Texas: University of Texas Press.

Beraldo, B. (no prelo).Dinâmicas de intersubjetividade nos processos de negociação e construção de significados em fóruns de discussão no ensino médio. Tese de duplo doutorado não- 
publicada, Programa de Pós-Graduação em Desenvolvimento Humano e Saúde, Universidade de Brasília e Programa de PósGraduação em Psicologia da Università Degli Studi di Parma, Emília-Romana, Itália.

Beraldo, R. M. F. (2013). Processos de desenvolvimento e formação de professores do ensino médio para o uso das novas tecnologias em práticas educativas. Dissertação de mestrado, Programa de Pós-Graduação em Desenvolvimento Humano e Saúde, Universidade de Brasília. Recuperado: 15 de fev. 2015. Disponível: http://repositorio.unb.br/bitstream/10482/13115/1/2013_ RossanaMaryFujarraBeraldo.pdf

Beraldo, R. \& Barbato, S. (2013). Instrumentos pedagógicos para preparação de aulas com o uso das TIC e da Internet. Mod.2. Curso de atualização em práticas pedagógicas para professores da Secretaria de Educação do Estado da Bahia. Brasília: CEAD/ UnB.

Bereiter, C. (1997). Situated cognition and how to overcome it. Em D. Kirshner \& J. A. Whitson (Orgs.), Situated cognition: Social, semiotic, and psychological perspectives (pp. 281-300). Hillsdale, $\mathrm{NJ}$ : Erlbaum.

Brown, R. \& Renshaw, P. (2006).Positioning students as actors and authors: a chronotopic analysis of collaborative learning activities. Mind, Culture, and Activity, 13(3), 247-259.

Deci, E. (1992). The relation of interest to the motivation of behavior: a self-determination theory perspective. Em K. A. Renninger, S. Hidi, \& A.Krapp (Orgs.), The role of interest in learning and development. New Jersey: Lawrence Erlbaum Associates Publisher.

Engeström, Y. 2007. Enriching the Theory of Expansive Learning: lessons from journeys toward co-configuration.Mind, Culture and Activity,14(1), 23-39.

Joly, M. C. R. A., Silva, B. D., \& Almeida, L. S. (2012).Avaliação das competências docentes para a utilização das tecnologias digitais da comunicação e informação. Currículo sem Fronteiras, 12 (3), 83-96.

Leontiev, D. A. (1992). Join activity communication and interaction: toward well-grounded pedagogy of cooperation. Journal of Russian and East European Psychology, 30(2), 43-58.

Lavinas, L. \& Veiga, A. (2013). Desafios do modelo brasileiro de inclusão digital pela escola. Cadernos de Pesquisa, 43(149), 542569.

Lévy, P. (1996). O que é virtual? (Neves, P., Trad.). São Paulo: Ed. 34.

Ligorio, M. B. (2010). Dialogical relationship between identity and learning. Culture Psychology, 16, 93-107.

Littleton, K. \& Mercer, N. (2013). Interthinking: putting talk to work. London, UK: Routledge.
Lorenzoni, I. (2012) Tecnologia na educação. Ministério distribuirá tablets a professores do ensino médio. Brasília: Ministério da Educação. Recuperado: 15 fev. de 2015. Disponível: http://portal. mec.gov.br/

Maciel, D. A., Branco, A. U., \& Valsiner, J. (2004). Bidirecional process of knowledge construction in teacher-student transaction. Em A. U. Branco \& J. Valsiner (Orgs.),.Communication and metacomunication in Human Development. Connecticut: IAP.

Maciel, D. A. (2008). Processos motivacionais e inclusão escolar: contribuições à formação do professor de artes. Em D. A. Maciel \& L. H. Pulino (Orgs.), Módulo 5: A Psicologia e a construção do conhecimento. Brasília: Cidade Gráfica Editora.

Maciel, D. A. \& Raposo, M. B. T. (2010). Metodologia e construção do conhecimento: contribuições para o estudo da inclusão. Em D. A., Maciel \& S. Barbato (Orgs.),.Desenvolvimento humano, educação e inclusão escolar. Editora Universidade de Brasília: Brasília.

Matusov, E. (1996). Intersubjectivity without agreement. Mind, Culture and Activity, 3(1), 25-45.

Mercer, N. (2000). Words \& Minds: how we use language to think together. London: Routledge Taylor \& Francis Group.

Ministério da Educação (2015). Projeto Mídias na Educação. Brasília: Ministério da Educação. Recuperado: 15 fev. de 2015. Disponível: http://portal.mec.gov.br/

Oliveira, Z. M. F.(2010). Fatores influentes no desenvolvimento do potencial criativo. Estudos de Psicologia, 27(1), 83-92.

Palfrey, J. \& Gasser, U. (2011). Nascidos na era digital: entendendo a primeira geração de nativos digitais. Porto Alegre: Artmed.

Pontecorvo, C., Ajello, A. M., \& Zucchermaglio, C. (2005). Discutindo se aprende: interação social, conhecimento e escola (Bressan, C. \& Termignoni, S., Trads.). Porto Alegre: Artmed.

Rey, F. G. (2003). Sujeito e subjetividade (Guzzo, R. S. L., Trad.). São Paulo: Pioneira Thomson.

Rueda, R. \& Moll, L. (1994). A sociocultural perspective on motivation. Em H. F. O'Neil \& M. Drillings (Orgs.). Motivation: research and theory (pp. 117-140). New Jersey: Lawrence Erlbaum Associates Publisher.

Scorsolini-Comin, F. (2014). Psicologia da educação e as tecnologias digitais de informação e comunicação. Psicologia Escolar e Educacional,18(3), 447-455.

Serres, M. (2013). Polegarzinha: uma nova forma de viver em harmonia, de pensar as instituições, de ser e de saber (Bastos, J., Trad.). Bertrand Brasil: Rio de Janeiro. 
Tancredi, L. (2008). Educação à distância. Mais escolas terão banda larga. Recuperado: 15 fev. de 2015. Disponível: http://portal.mec.gov.br/

Wegerif, R. (2005). Reason and creativity in classroom dialogues. Language and Education, 19(3), 223-238.

Wertsch, J. V. (1988). Mind as action. Oxford University Press, New York.

Valsiner, J. (2012). Fundamentos da Psicologia cultural: mundos da mente, mundos da vida (Bastos, A. C. S., Trad.). Porto Alegre: Artmed.
Versuti, A. C., Beraldo, R., \& Gosciola, V. (2014). Formação de professores, transmídia, conhecimento e criatividade: novas linguagens, teorias e práticas para o professor contemporâneo(Vol. II). Recife: UFPE. Disponível: https://www.ufpe.br/editora/ ufpebooks/outros/form_prof_2/

Vigotski, L. S. (2009). A construção do pensamento e da linguagem (Bezerra, P., Trad.). São Paulo: Martins Fontes. (Trabalho original publicado em 1934).

Recebido em: 03/02/2015

Reformulado em: 22/02/2016

Aprovado em: 13/04/2016

\section{Sobre as autoras}

Rossana Mary Fujarra Beraldo (rossanaberaldo@gmail.com)

Mestre pelo Programa de Pós-graduação em Processos de Desenvolvimento Humano e Saúde da Universidade de Brasília. Estudante em duplo doutorado em Psicologia pela Universidade de Brasília e Università degli Studi di Parma (Itália). Bolsista Capes.

Diva Albuquerque Maciel (divamaciel52@gmail.com)

Mestre em Psicologia pela Universidade de Brasília, doutora em Educação pela Universidade de São Paulo e estudo Pós-doutoral na Clark University. Docente do Instituto de Psicologia (IP/UnB), Departamento de Psicologia Escolar e do Desenvolvimento (PED), Programa de PósGraduação em Processos de Desenvolvimento Humano e Saúde (PGPDS), Campus Universitário Darcy Ribeiro, Brasília.

Artigo oriundo de dissertação de mestrado. 
